\title{
Mastoid osteoma: report of a case and literature review
}

\section{Patrícia M. S. Takenaka', Filomena R. P. Perez ${ }^{2}$, Sandra J. Patrocínio ${ }^{3}$, Juparethan T. Ribeiro ${ }^{4}$}

Key words: osteoma, mastoid bone.

\section{Summary}

steo ma of the mastoid is a rare benign bone-forming tumor composed by bone tissue. It is a slow growing tumor that is kept stable for years. Normally it is asymptomatic, although it may cause cosmetic deformities most of the time. Its differential diagnosis presents mostly temporal bone isolated lesions, such as monostotic fibrous dysplasia and osteoid osteoma. In the present study the authors make a review of the literature on osteoma of the mastoid and describe one case.

${ }^{1}$ Master studies in Otorhinolaryngology under course, Santa Casa de Sao Paulo. Assistant physician, Department of Otorhinolaryngology, Hospital Servidor Público Municipal.

${ }^{2}$ Assistant physician, Department of Otorhinolaryngology, Hospital Servidor Público Municipal.

${ }^{3}$ Resident physician in Otorhinolaryngology, Hospital Servidor Público Municipal.

${ }^{4}$ Resident physician in Otorhinolaryngology, Hospital Servidor Público Municipal.

Affiliation: Department of Otorhinolaryngology, Hospital Servidor Público Municipal, Sao Paulo.

Address correspondence to: Patrícia M.S. Takenaka - Rua Bartolomeu de Gusmão 412 apto 12 Vila Mariana Sao Paulo $04111-021$. Tel (55 11) 5573-4867 - E-mail: ptakenaka@uol.com.br

Study presented at 360 Congresso Brasileiro de Otorrinolaringologia, held in Florianópolis, on November 19 to 23, 2002.

Article submited on October 10, 2003. Article accepted on July 15, 2004. 


\section{INTRODUCTION}

Osteomas are benign bone tumors of the head and neck that are frequently found in the frontal-ethmoid region 1,2 . In the temporal bone, the external auditory canal is the predominant location, rarely present in the mastoid, the squamous portion of the temporal bone, inner ear canal and middle ear ${ }^{3}$. When located in the mastoid they are solitary, sessile or pediculated and normally they progress to extracranial grow th 2,4,5. Even though most mastoid osteomas do not cause significant symptoms, they should be given attention by the O torhinolaryngologists because they can lead to esthetical alterations and occasionally to functional ones 5 .

The purpose of the present study was to present a review of the literature about mastoid osteomas and to report in details the case of a patient with the lesion.

\section{UTERATURE REVEW}

Stuart defined the term mastoid osteoma as a bone tissue tumor of the mastoid, benign, circumscribed and of slow growth 5,6 . The size may vary and in general they are smaller than $3 \mathrm{~cm}$ during the first examination ${ }^{5}$.

It has higher incidence in female patients, predominantly in the $2^{\text {nd }}$ and $3^{\text {rd }}$ decades of life and it is rare in puberty ${ }^{4,5,7}$.

Its etiology is still undefined, but there are many different theories:

- The most accepted theory: it suggests that the tumor grows from pre-bone connective tissue ${ }^{1,2,5}$;

- Congenital theory: its manifestation happens when bone growth is intensified (puberty), with presence of embryonic cartilage ${ }^{7}$;

- Traumatic theory: as a consequence of periostitis ${ }^{5}$;

- Infectious theory: in cases of otitis media, with greater influence of middle ear osteoma 8 ;

- Hormone theory: in which there is increase of periosteal osteoblast activity, stimulated by endocrine mechanisms ${ }^{7,9}$;

- Hereditary factors 5 .

It presents clinically as a slow growth tumor, remaining stable for years. It may produce external deformity and push the pinna forward 6 . Even though it is normally asymptomatic, itmay produce pain by invasion of neighboring structures or widening of periosteum; the pain in this case is related to internal cortical lamina involvement 2,5 . If located in the external auditory canal, it may lead to occlusion, progressing to chronic external otitis (30\% of the cases) and conductive hearing loss ${ }^{2,4,7}$. As complications, we can include recurrence, facial nerve affection, sigmoid sinus damage and sensorineural hearing loss, by nervous compression of inner ear $^{2,3,5,8}$.
The radiological aspect enables diagnosis: welldelimited lesion situated in the mastoid, normally single, regular, with bone density given that it is formed by cortical compact dense bone ${ }^{10}$. Microsco pically, it presents a cover of cortical bone, adjacent to an area of connective tissue. Below the cortical bone, there are trabecullae of spongy bone, ranging in vascularization and amount of fibrous tissue present ${ }^{7}$.

Three types of mastoid osteomas have been described, based on structural characteristics $2,6,9,10$ :

- Compact: the most frequent one. Comprising dense, compact and lamellar bone, with few vessels and Havers canals;

- Cartilaginous: comprising bone and cartilaginous elements;

- Spongy: rare type. Comprised by spongy bone and fibrous cell tissue, with tendency to expand to the diploe and involving the internal and external lamina of the affected bone;

- Mixed: mixture of spongy and compact types ${ }^{1}$.

Clinical and radiological findings are sufficiently suggestive of osteoma, however, we should bear in mind the importance of differential diagnosis with other temporal bone isolated lesions, such as: eosinophilic granuloma, with specific radiological images, monostotic fibrous dysplasia, with precise histological characteristics; giant cell tumor, solitary multiple myeloma; osteosarcoma and osteoid osteoma, differentiating them by pain caused by them, presence of active chemicals and characteristics of histological structures ${ }^{1-3,7}$. Exostosis, hyperostosis and endostosis are differentiated from osteoma because they are partially hypertrophic, circumscribed to bone surface and many times concomitant to infectious toxic or irritative processes, with histological differentiation based on absence or presence of fibrovascular channels 3,7 .

The surgical treatment is indicated in symptomatic lesions and esthetical deformities 9,10 .

\section{CASE REPORT}

Female 55-year-old patient seen in the Ambulatory of Otorhinolaryngology, Hospital Servidor Público Municipal, in April 2002, complaining of lump behind the right ear for 49 years. She reported that the grow th started at the age of 2 years, stabilizing at 14 years, without pain or any other otological complaint. As to personal history, she did not report trauma or infectious process of the region in study. The physical examination showed tumor of approximately $2.5 \mathrm{~cm}$ on the right retroauricular region, of bone consistence, smooth surface, rounded, not movable, with no phlogistic signs (Figure 1). In otoscopy, the external acoustic canal had no affections and the tympanic membrane was normal.

Audiometry revealed bilateral symmetric mild 
sensorineural hearing loss. The radiological assessment was made by temporal bone CT scan showing hyperattenuating area close to the right mastoid cortex, measuring approximately $2.5 \mathrm{~cm}$, spherical, with cleavage areas between the tumor and the mastoid external cortex (Figures 2, 3).

The patient refused to be submitted to surgical procedure to remove the lesion because she did not present clinical symptoms and was not affected by the esthetical appearance of the lesion.

\section{DISCUSSION}

The clinical case reported here was diagnosed as mastoid osteoma owing to its clinical and radiological characteristics.

In the literature, the first publication of mastoid osteoma was made in 1887 by Adam Politzer, in his book?; since then, isolated cases of this benign tumor have been published.

In the present study, a piece of data that attracted our attention was age at the onset of the lesion (2 years), different from the literature that reports it as more frequent in the $2^{\text {nd }}$ and $3^{\text {rd }}$ decades of life. How ever, the absence of symptoms such as pain confirms that mastoid osteomas in most cases are asymptomatic, as a result of the frequent stabilization of the lesion, which in our case had already occurred 41 years before.

Sensorineural hearing loss observed in the case is justifiable probably by presbyacusis, but there was no correlation with the studied damage.

Mastoid osteoma reported in the abovementioned case is probably of compact type since it presented some characteristics such as spherical shape, fixed to mastoid cortex, but it may have penetrated mastoid cells. This was not a complete conclusion because the surgical exeresis was not performed and there was no clinical pathology analysis.

The surgery was not performed owing to the patient's own decision, who is still under outpatient follow-up. As referred before, it is not mandatory, but if performed, the surgery should include careful removal of periosteal cover and safe margin of the mastoid cortical around it ${ }^{4}$. If the tumor is close to significant structures such as bone labyrinth and facial nerve canal, a subtotal excision ensures preservation of function, required in postoperative follow-up. We should be very careful when providing intervention of tumors close to sigmoid sinus, because they can progress with significant bleeding, meningitis, thrombophlebitis and ophthalmologic complications ${ }^{2,4}$.

\section{CLOSING REMARKS}

Anamnesis and examination are extremely important in the diagnosis of mastoid osteoma, which may be left unnoticed in many situations considering its asymptomatic

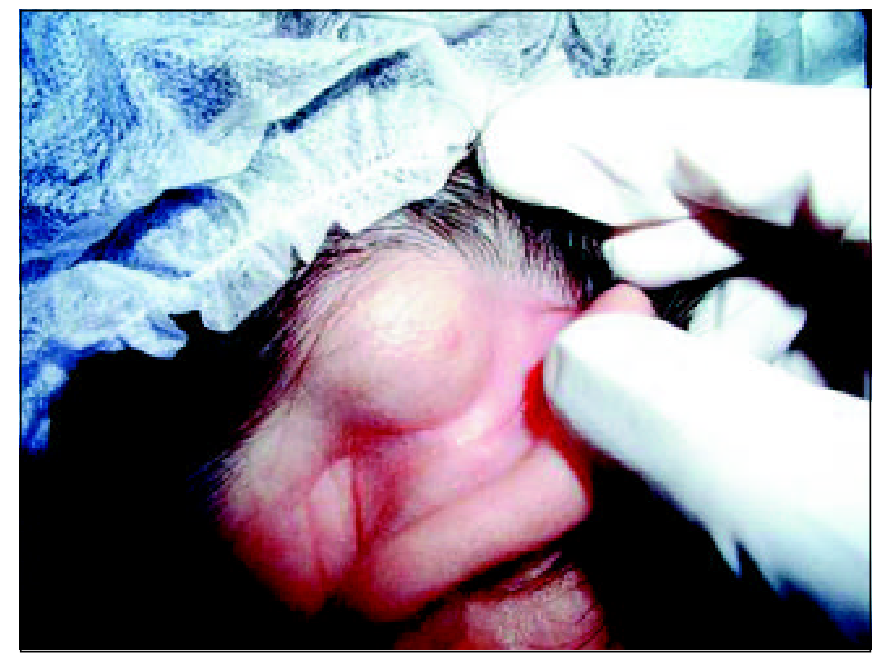

Figure 1. Visualization of retroauricular tumor on the right.

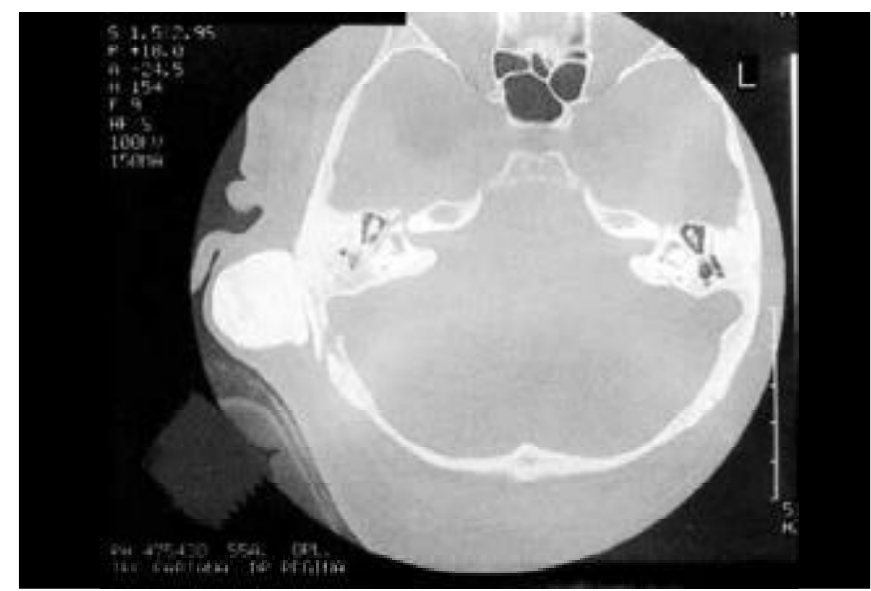

Figure 2. Temporal bone CT scan showing hyperattenuating lesion close to the right mastoid cortex.

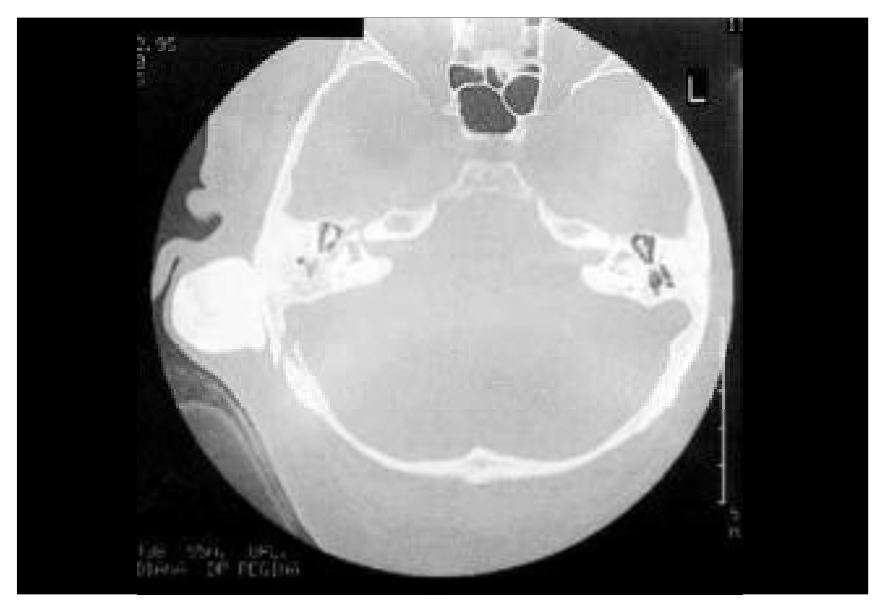

Figure 3. Temporal bone CT scan showing hyperattenuating lesion on the right, without inner ear canal involvement. 
nature. Continuous follow-up of the patient will help decide on the most appropriate management approach.

\section{REFERENCES}

1. Probst LE, Shankar L, Fox R. Osteoma of the mastoid bone. J Otolaryngol 1991; 20(3): 228-30.

2. Burton DM, Gonzalez C. Mastoid osteomas. Ear Nose Throat J 1991; 70(3): 161-2.

3. Camacho RR, Vicente J, Cajal SR. Imaging quis case 2. Arch Otolaryngol Head Neck Surg 1999; 125(3): 349, 251-352.

4. Gupta OP, Samant IIC. Osteoma of the mastoid. Laryngoscope 1972; 82(2): 172-6.
5. Denia A, Perez F, Canalis RR, Graham MD. Extracanalicular osteomas of the temporal bone. Arch Otolaryngol 1979; 105(12): 706-9.

6. Fleming JP. Osteoma of the mastoid. Can J Surg 1966; 9(4): 402-5.

7. Clarós P, Pulido MV, Clarós A, Pulido R. Los osteomas de la mastoides. An Otorrinolaringol Ibero Am 1978; 5(2): 279-91.

8. Tutor EG. Osteoma de mastoides. An otorrinolaringol Ibero Am 1991; 18(4): 325-30.

9. Singh I, Sanasam JC, Bhatia PL, Singh LS. Giant osteoma of the mastoid. Ear Nose Throat J 1979; 58(6): 243-5.

10. Guérin N, Chauveau E, Julien M, Dumont JM, Merignargues G. Ostéome de la mastoïde: à propôs de deux cas 1996; 117(2): 127-32. 